\title{
The Treebanks Used in the Shared Task
}

This page contains references to all the treebanks used in the CoNLL-X shared task. This page should be consulted whenever a shared task paper refers to a treebank without including the actual reference.

\section{References}

A. Abeillé, editor. 2003. Treebanks: Building and Using Parsed Corpora, volume 20 of Text, Speech and Language Technology. Kluwer Academic Publishers, Dordrecht.

S. Afonso, E. Bick, R. Haber, and D. Santos. 2002. "Floresta sintá(c)tica": a treebank for Portuguese. In Proc. of the Third Intern. Conf. on Language Resources and Evaluation (LREC), pages 1698-1703.

N. B. Atalay, K. Oflazer, and B. Say. 2003. The annotation process in the Turkish treebank. In Proc. of the 4th Intern. Workshop on Linguistically Interpreteted Corpora (LINC).

A. Böhmová, J. Hajič, E. Hajičová, and B. Hladká. 2003. The PDT: a 3-level annotation scenario. In Abeillé (Abeillé, 2003), chapter 7.

S. Brants, S. Dipper, S. Hansen, W. Lezius, and G. Smith. 2002. The TIGER treebank. In Proc. of the First Workshop on Treebanks and Linguistic Theories (TLT).

K. Chen, C. Luo, M. Chang, F. Chen, C. Chen, C. Huang, and Z. Gao. 2003. Sinica treebank: Design criteria, representational issues and implementation. In Abeillé (Abeillé, 2003), chapter 13, pages 231-248.

M. Civit, Mª A. Martí, B. Navarro, N. Bufi, B. Fernández, and R. Marcos. 2003. Issues in the syntactic annotation of Cast3LB. In Proc. of the 4th Intern. Workshop on Linguistically Interpreteted Corpora (LINC).

M. Civit Torruella and $\mathrm{M}^{\mathrm{a}}$ A. Martí Antonín. 2002. Design principles for a Spanish treebank. In Proc. of the First Workshop on Treebanks and Linguistic Theories (TLT).

S. Džeroski, T. Erjavec, N. Ledinek, P. Pajas, Z. Žabokrtsky, and A. Žele. 2006. Towards a Slovene dependency treebank. In Proc. of the Fifth Intern. Conf. on Language Resources and Evaluation (LREC).

J. Hajič, O. Smrž, P. Zemánek, J. Šnaidauf, and E. Beška. 2004. Prague Arabic dependency treebank: Development in data and tools. In Proc. of the NEMLAR Intern. Conf. on Arabic Language Resources and Tools, pages 110-117.
Y. Kawata and J. Bartels. 2000. Stylebook for the Japanese treebank in VERBMOBIL. VerbmobilReport 240, Seminar für Sprachwissenschaft, Universität Tübingen.

M. T. Kromann. 2003. The Danish dependency treebank and the underlying linguistic theory. In Proc. of the Second Workshop on Treebanks and Linguistic Theories (TLT).

B. Navarro, M. Civit, M $^{\mathrm{a}}$ A. Martí, R. Marcos, and B. Fernández. 2003. Syntactic, semantic and pragmatic annotation in Cast3LB. In Proc. of the Workshop on Shallow Processing of Large Corpora (SPro$\mathrm{LaC}$ ).

J. Nilsson, J. Hall, and J. Nivre. 2005. MAMBA meets TIGER: Reconstructing a Swedish treebank from antiquity. In Proc. of the NODALIDA Special Session on Treebanks.

K. Oflazer, B. Say, D. Zeynep Hakkani-Tür, and G. Tür. 2003. Building a Turkish treebank. In Abeillé (Abeillé, 2003), chapter 15.

P. Osenova and K. Simov. 2004. BTB-TR05: BulTreeBank stylebook. BulTreeBank version 1.0. Bultreebank project technical report. Available at: http://www.bultreebank.org/TechRep/BTB-TR05.pdf.

K. Simov and P. Osenova. 2003. Practical annotation scheme for an HPSG treebank of Bulgarian. In Proc. of the 4th Intern. Workshop on Linguistically Interpreteted Corpora (LINC), pages 17-24.

K. Simov, G. Popova, and P. Osenova. 2002. HPSGbased syntactic treebank of Bulgarian (BulTreeBank). In A. Wilson, P. Rayson, and T. McEnery, editors, $A$ Rainbow of Corpora: Corpus Linguistics and the Languages of the World, pages 135-142. Lincom-Europa, Munich.

K. Simov, P. Osenova, and M. Slavcheva. 2004. BTB-TR03: BulTreeBank morphosyntactic tagset. BTB-TS version 2.0. Bultreebank project technical report. Available at: http://www.bultreebank.org/TechRep/BTB-TR03.pdf.

K. Simov, P. Osenova, A. Simov, and M. Kouylekov. 2005. Design and implementation of the Bulgarian HPSG-based treebank. In Journal of Research on Language and Computation - Special Issue, pages 495522. Kluwer Academic Publishers.

L. van der Beek, G. Bouma, R. Malouf, and G. van Noord. 2002. The Alpino dependency treebank. In Computational Linguistics in the Netherlands (CLIN). 